\title{
Correlates of self-reported physical health status of students of the University of Ibadan, Nigeria
}

\author{
T. B. Alagh and F. O. Omokhodion* \\ Medical Department, Federal Airports Authority of Nigeria, \\ Kaduna International Airport, Kaduna. \\ *Department of Community Medicine, University College Hospital, Ibadan.
}

E-mail: dhf.omokhodion@skannet.com

\begin{abstract}
Summary
Background: Young people including university students are a justifiable target for health status assessment as they form a large group that only recently escaped the adverse mortality experiences of childhood. This study was conducted in the University of Ibadan to determine the state and correlates of students' physical health.

Study design: Seven hundred and fifty students were randomly selected from all eleven halls of residence by multi stage sampling. Questionnaires derived from the Duke Health Profile, a generic health instrument were administered by trained student peers and responses scored using the recommended guidelines.

Results: The overall response rate was $96.5 \%$. The sample consisted of 484 males and 240 females; 602 undergraduate and 122 graduate students giving a male: female ratio of 2: 1 and undergraduate: graduate student ratio of 5:1, similar to the ratio in the 18,690 strong general student body. All the university's faculties were represented. Most (92.3\%) of the respondents were single. The group had a mean age of 23.8 years (SD 4.6). The mean physical health score was 7.9 (SD 1.67) out of a possible maximum of 10. High scores were significantly associated with male gender and frequent exercise. Sixteen students $(2.2 \%)$ reported a physical handicap and $122(16.3 \%)$ a medically diagnosed chronic illness. A mean of 1.14 days of disability occurred among the students in the month preceding the survey. Common causes of morbidity reported included fever $(59.8 \%)$, nervousness $(12.4 \%)$, cough (12.3\%) and sleeping disorders $(11.2 \%)$.

Conclusion: The high mean physical health score recorded in this study indicates that students have an overall good level of functioning. However physical health status was associated with several lifestyle and personal factors.
\end{abstract}

Key -words: University students, Physical health status, Self reported health status, Life styles

\section{Résumé}

Introduction: Des jeunes y compris des étudiants à l'université sont une cible justifiable pour l'évaluation du statut de la santé parce qu'ils constituent un groupe nombreux qui a tout récemment échappé des expériences adverses de la mortalité d'enfance. Cette étude a été effectuée à l'université d'Ibadan afin de décider l'état et les correlations de la santé physique des étudiants.

Plan d'étude: Sept cents et cinquante étudiants ont été choisis au hasard à partir de onze résidences universitaires à travers la méthode du prélevement d'echantillons à plusieurs étages. Questionnaire tirés du profil de Sante de Duke un instrument générique de santé ont été administrés par des étudiants en pairs bien formés et on avait noté des réponses à travers l'utilisation des directives recommandées.

Résultats: Dans l'ensemble, le taux de réponse était $96,5 \%$. L'échantillon consisstait en 484 du sexe masculin et $240 \mathrm{du}$ sexe féminin; 602 etudiants et 122 licenciés donnant un raport de sexe masculin : sexe féminin 2: 1 et un rapport d'étudiants : licenciés 5:1 semblable au rapport chez 18,690 foule nombreuse des étudiants en général. Toute les facultés de l'université ont été représentées. La plupart des sondés $(92,3 \%)$ était célibataires. Le groupe avait l'âge moyen de 23,8 ans (SD 4,6). Le score physique de la santé moyenne était 7,9 (SD 1,67) parmi un maximum possible de 10.

Des scores élevés étaient principalement liés au sexe masculin et au exercice fréquent seize étudiants $(2,2 \%)$ avaient signalé le cas d'handicap physique et 122 soit 16,3\% une maladie chronique diagnostiquée médicalement. Un moyen de 1;14 jours d'infirmité était arrivé parmi des étudiants dans le mois précédent d'étude. Les causes ordinaires responsable pour la morbidité signalées comprend la fièvre $59,8 \%$, nervosité $12,4 \%$ la toux $12,3 \%$ et troubles du sommeil $11,2 \%$.

Conclusion: Le moyen du score élevé de la santé physique noté dans cette étude montre que des étudiants on un bon niveau du fonctionnement dans l'ensemble. Toutefois, status de santé physique est lié aux diverses mode de vie et facteurs personnel.

\section{Introduction}

The health of students has been the subject of extensive research. Most of this effort has however been focussed on sexuality and reproductive health concerns to the neglect of other important health issues. This trend is not unique to Nigeria. An American College Health Association task force which studied national health objectives to determine how well colleges (universities) were achieving nationally defined goals found that college age populations were not specially recognised as a concern among planners and that little consistent data on their health status existed. 'Worsening socio economic conditions such as overcrowding in our institutions, the occurence of anti-social activities including cult violence and sexual harassment, all suggest the presence of factors that may affect the health of students. The poor health system in the country often means that most students have never had a proper medical examination before entering the university. The prevailing low literacy levels in society also mean that university students become models of good social values for their peers and communities. All these make attention to their state of health vital. ${ }^{2}$

An exploratory study was therefore designed to provide this baseline data among students in the University of Ibadan, 
Nigeria's foremost tertiary institution to determine the prevalence of health-related practices and assess the health status of students using the technique of self reporting and health assessment.

\section{Method}

The University of Ibadan is Nigeria's oldest university having been in existence for over 50 years. It had a 1997 student population of 18,690 , in ten faculties, colleges and institutes and housed in 11 halls of residence. This cross sectional study was carried out in 1998. Seven hundred and fifty students were selected from the halls of residence using a multi stage sampling technique in each hall. The rooms constituted the primary sampling units and were selected using a sampling fraction of 1 in 4 . The first room visited was randomly chosen by balloting. The second stage-sampling units were the occupants of the selected rooms. One of these was selected by balloting. Pre tested questionnaires, adapted from the Duke UNC Health Profile ${ }^{3}$ and its later revision, the Duke Health Profile ${ }^{4}$ were administered to these respondents by trained interviewers, who were second year medical students. Rooms were visited between 7 and 9 p.m. on weekdays. Where any of the room occupants refused to participate in the ballot or the selected student declined to fill the -questionnaire, this was recorded as a refusal. Fifteen such occasions were recorded in the study. The questionnaire enquired about demographic characteristics of students including social habits like smoking and drinking.

The Physical Health Score was computed from the following five questionnaire items. If you tried today, how much physical difficulty will you have; running 5 kilometres, walking up a flight of stairs, running the distance from the main gate to hostel, running the length of a football field and lifting a bucket of water. These responses were scored as follows: "None" scored 2 "some" scored 1 and "A Lot" scored 0 . The items scored were then summed to get a physical health score in accordance with the guidelines established by the authors of Duke Health Profile. High scores indicated better functional capacity. Other items used to evaluate physical health included prevalence of doctors - confirmed chronic medical conditions, common cause of morbidity, prevalence of disability and handicap, and number of days of disability and restricted activity days in the month preceding the survey. All returned questionnaires were screened for completeness. Those with more than $25 \%$ of questions unanswered were discarded. The data was managed using the Epilnfo statistical package version $6.04 \mathrm{~b}$.

\section{Results}

Altogether, 750 students were surveyed in this study with 724 returning completed questionnaires. The response rate was $96.5 \%$. The general characteristics of the students are summarized in Table 1 . Of the 724 whose questionnaires were entered for analysis, $484(66.9 \%)$ were males and 240 females. 602 undergraduate and 122 graduate students. The male to female and undergraduate to postgraduate students ratio were $2: 1$ and $5: 1$ respectively, approximately the same as in the student body.

The mean age of the sample was 23.8 (SD 4.6) years with range 17 to 45 . Overall, female undergraduates were younger (mean 22.8 SD 4.1) than their male counterparts (mean 24.3, SD 4.7), $p=0.000015$. Six hundred and sixty-seven were single (92.3\%) 8 were divorced or separated and $41(6.6 \%)$ were married. Six hundred and twelve $(84.4 \%)$ were Christians and $100(13.8 \%)$ Muslims.

The respondents were drawn from all the faculties in the university. These were grouped into three related disciplines as follows: Medical Sciences including Medicine, Dentistry, Pharmacy, Nursing, Physiotherapy, Biochemistry, Physiology and Human Nutrition (28.1\%). Sciences and Technology including Technology, Engineering, Physical Sciences, Agriculture and Veterinary Medicine $(30.7 \%)$ and Arts and Humanities including Social Sciences, Law and Education (41.2\%).

\section{Smoking, alcohol use and recreational physical activity}

Of the 724 respondents, $41(5.7 \%)$ were current smokers and $127(17.5 \%)$ former smokers giving an ever-smoked prevalence of $23.2 \%$. Prevalence rates for alcohol use were higher, $179(24.7 \%)$ and $(46.1 \%)$ for current and ever used prevalence respectively. More than a quarter of students, 207 do not engage in any form of exercise. Only $12(1.8 \%)$ reported exercising daily and $208(28.7 \%)$ for 3 or more days in a week as recommended. ${ }^{5}$ The most common forms of exercise reported included press-ups, walking and jogging.

\section{Physical health score}

The physical health score is a composite index con-

Table 1 Socio demographic characteristics of students of the university of Ibadan

\begin{tabular}{lcc}
\hline & Males N (\%) & Females N (\%) \\
Age & & \\
$16-20$ & $110(24 \%)$ & $66(38.8 \%)$ \\
$21-25$ & $200(43.6 \%)$ & $123(53.7 \%)$ \\
$26-30$ & $113(24.6 \%)$ & $30(13.1 \%)$ \\
$31-35$ & $22(4.8 \%)$ & $6(2.6 \%)$ \\
$36 \&$ above & $14(3.1 \%)$ & $4(1.8 \%)$ \\
Total & $459(100 \%)$ & $229(100 \%)$ \\
Level of study & & \\
Postgraduate & $80(16.5 \%)$ & $42(17.7 \%)$ \\
Undergraduate & $404(83.5 \%)$ & $196(82.3 \%)$ \\
No. of occupants per room & \\
$1-5$ persons & $332(68.6 \%)$ & $91(38.2 \%)$ \\
6- 10 persons & $150(31 \%)$ & $11(46.6 \%)$ \\
11 + persons & $2(0.4 \%)$ & $36(15.1 \%)$ \\
Total & $484(100 \%)$ & $238(100 \%)$ \\
Mean & 4.4 & 6.7 \\
Smoking prevalence & & \\
Former smoker & $105(21.7 \%)$ & $23(9.6 \%)$ \\
Currently smoke & $32(6.6 \%)$ & $9(3.8)$ \\
Never smoked & $347(71.7 \%)$ & $208(86.7)$ \\
Alcohol intake & & \\
Never drank & $218(45.0 \%)$ & $173(72.1 \%)$ \\
Ever drank & $266(55 \%)$ & $67(27.9 \%)$ \\
Current drinker & $140(28.9 \%)$ & $39(16.3 \%)$ \\
Binge drinkers & $141(29.1 \%)$ & $21(8.8 \%)$ \\
\hline - & &
\end{tabular}


Table 2 Physical health scores of students of the university of Ibadan and various study variables

\begin{tabular}{|c|c|c|c|c|c|}
\hline \multirow[t]{2}{*}{ Variable } & Groups & $\begin{array}{l}\text { Mean physical } \\
\text { health scores }\end{array}$ & Test & D.F & $\mathbf{P}$ \\
\hline & Male & 8.13 & & & \\
\hline Gender & Female & 7.44 & $T=5.25$ & 1 & 0.000001 \\
\hline Course & Arts & 7.7 & & & \\
\hline \multirow[t]{2}{*}{ Group } & Science & 7.9 & $F=13.87$ & 2 & 0.00097 \\
\hline & Medical & 8.3 & & & \\
\hline No of & $1-5$ & 8.09 & & & \\
\hline Occupants & $6-10$ & 7.77 & $\mathrm{H}=17.56$ & 2 & 0.00015 \\
\hline \multirow[t]{2}{*}{ per room } & $11-15$ & 7.0 & & & \\
\hline & $16-20$ & 8.06 & & & \\
\hline Age & $21-25$ & 8.09 & & & \\
\hline \multirow[t]{3}{*}{ (years) } & $26-30$ & 8.14 & & & \\
\hline & $31-35$ & 7.79 & $\mathrm{H}=7.74$ & 4 & 0.1 \\
\hline & $>35$ & 7.47 & & & \\
\hline Study & UG & 7.93 & & & \\
\hline Level & PG & 7.74 & $T=1.18$ & 1 & 0.24 \\
\hline \multirow[t]{3}{*}{ Smoking } & Never & 7.93 & & & \\
\hline & Former & 7.9 & & & \\
\hline & Current & 7.5 & $F=1.19$ & 2 & 0.31 \\
\hline Alcohol & Never & 7.94 & & & \\
\hline \multirow[t]{2}{*}{ Intake } & Former & 7.89 & $\mathrm{~F}=0.27$ & 2 & 0.77 \\
\hline & Current & 7.83 & & & \\
\hline Level of & Adequate & 8.14 & & & \\
\hline Exercise & Inadequate & 7.82 & $\mathrm{~T}=2.17$ & 1 & 0.031 \\
\hline
\end{tabular}

Table 3 Number of days of disability reported by students of the university of Ibadan and relationship with other study variables.

\begin{tabular}{|c|c|c|c|c|c|c|c|c|}
\hline Variable & Groups & 0 & $1-3$ & $4-6$ & $>7$ & $\begin{array}{l}\text { Degrees } \\
\text { of freedom }\end{array}$ & $\begin{array}{c}\text { Test } \\
\text { statistic }\end{array}$ & $\mathbf{P}$ \\
\hline \multirow[t]{5}{*}{ Age } & $16-20$ & 149 & 76 & 18 & 9 & & & \\
\hline & $21-25$ & 180 & 61 & 26 & 2 & & & \\
\hline & $26-30$ & 80 & 28 & 3 & 0 & & & \\
\hline & $31-35$ & 16 & 5 & 0 & 0 & 3 & $H=14.75$ & 0.0002 \\
\hline & $>35$ & 41 & 3 & 1 & 0 & & & \\
\hline \multirow[t]{2}{*}{ Gender } & Male & 328 & 105 & 41 & & & & \\
\hline & Female & 132 & 75 & 26 & & 2 & $X^{2}=11$ & 0.004 \\
\hline Study & UG & 376 & 149 & 65 & & & & \\
\hline Level & PG & 84 & 31 & 2 & & 2 & $X^{2}=9.96$ & 0.0069 \\
\hline \multirow[t]{3}{*}{ Course } & Arts & 184 & 81 & 24 & & & & \\
\hline & Science & 147 & 50 & 21 & & 4 & $X^{2}=2.56$ & 0.63 \\
\hline & Medical & 129 & 49 & 22 & & & & \\
\hline \multirow[t]{2}{*}{ Handicap } & Yes & 12 & 4 & & & & & \\
\hline & No & 446 & 243 & & & 1 & $X 2=0.72$ & 0.4 \\
\hline Current & No & 439 & 228 & & & & & \\
\hline Smoking & Yes & 21 & 19 & & & 1 & $X 2=0.72$ & 0.086 \\
\hline \multirow[t]{3}{*}{ Drinking } & Never & 248 & 99 & 32 & & & & \\
\hline & Former & 113 & 25 & 14 & & 4 & $\mathrm{X} 2=0.72$ & 0.01 \\
\hline & Current & 99 & 56 & 21 & & & & \\
\hline
\end{tabular}

structed from five items covering physical functional capacity and symptoms. The possible range of scores is 0 to 10 . Higher scores indicate better physical functioning. Only 711 respondents $(94.8 \%)$ completed all the questions in this sec- tion. The students in this study had scores from 1 to 10 . The mean, median and modal scores of the group were 7.9 (SD 1.67), 8 and 8 respectively. The close proximity between these three measures of location indicated an underlying normal 
distribution. Thus, parametric tests were employed in measuring associations except where other conditions were not met. Two hundred and eighty five students $(40.1 \%)$ had scores above the third quartile and only $62(8.7 \%)$ scored 5 or less.

Table 2 shows the association between physical health scores and some demographic variables. While the male: female ratio in the sample was $2: 1$, the ratio among those with perfect score (10) was $3: 1$. The mean score for males was 8.13 (SD 1.51), significantly higher than the 7.44 (SD 1.87) means for females, $\mathrm{P}<0.000001$. "Medical" students scored highest with a mean of 8.25 (SD 1.46) and "Arts" students, lowest with a mean of 7.66 (SD 1.75). Again, this was statistically significant, $P=0.00097$. A greater proportion of undergraduate students (42\%) than postgraduate students $(30.6 \%)$ had scores above the thirtd quartile but this was not statistically significant, $P=0.24$. The mean physical health scores was higher among persons in rooms occupied by 5 or less ( $\mathrm{p}=$ $0.00015)$.

Physical health scores increased with increasing age up to 31 . The mean scores were 8.06 (SD 1.55), 8.09 (SD 1.75) and 8.14 (SD 1.49) for the $16-20,21-25$ and $26-30$ year age groups. Older students had the lowest mean scores with 31 - 35 year old scoring 7.79 (SD 1.66) and those over $35,7.47$ (SD 1.01). This association remained even when level of study and sex were controlled for but overall statistical significance was not attained.

Non-smokers and non-drinkers had slightly higher scores than their colleagues who smoke or drink though this was not statistically significant. However, students who exercised on 3 or more days of the week recorded significantly higher scores (8.14 SD 1.55) than those who either did not exercise at all or only did on one or two days of the week (7.82 SD 1.7), $p=0.031$.

\section{Physical handicap}

Of the 722 respondents to this question, $16(2.2 \%)$ were physically handicapped. Handicapping conditions reported were partial or total blindness 5 , limb paralysis or paresis, 9 and deafness 2 .

\section{Chronic medical conditions}

There were 122 students (16.3\%) with chronic medical conditions. Skin allergies, asthma and hypertension were the most common accounting for $48(39.3 \%), 36(28.7 \%)$ and $19(15.6 \%$ ) respectively. Of these 122 , only $60(49.5 \%)$ were seeing a doctor for their ailments with even less, $13(10.7 \%)$ keeping regular appointments.

\section{Common causes of morbidity}

Only 627 students selected a cause of morbidity; 59 did not respond and 38 indicated that none of these affected them. Fever was the most common complaint selected as most important by 375 respondents $(59.8 \%)$, followed by nervousness by $78(12.4 \%)$, cough by $77(12.3 \%)$ and sleeping disorders by $70(11.2 \%)$.

\section{Disability and restricted activity days}

Most of the respondents $(65.1 \%)$ reported no day of restriction due to an ailment in the month preceding the survey. The mean number of disability days was 1.14 (SD 0.7). Females reported disability days more frequently than males with $101(43.5 \%)$ so affected compared to $146(30.8 \%)$ among males. This was also more common among undergraduate students with $214(36.3 \%)$, compared to $33(28.2 \%)$ postgraduate students. These associations are statistically significant as shown in Table 3 . The mean age of respondents fell steadily as the number of disability days increased. Among those reporting no disability day the mean age was 24.1 but this fell to 20.3 years among students with 7 or more days, $P=\mathbf{0 . 0 0 0 2}$. There was no significant association with course of study.

Only $131(34.6 \%)$ of those who had never taken alcohol and $39(25.7 \%)$ of ex-drinkers reported any disability day compared to $77(43.8 \%)$ of current drinkers, $\mathrm{P}=\mathbf{0 . 0 1}$. Similarly, 228 (34.2\%) non-smokers compared to $19(47.5 \%)$ smokers reported any disability though this did not reach statistical significance at $5 \%$ level, $p=0.086$. Neither physical handicap nor chronic medical conditions were associated with disability days.

\section{Discussion}

The overall response rate in this study (96.5\%) is much better than that in previous university based studies. Direct surveying of student rooms and the use of student peers as research assistants made it possible to attain this response. An additional strength of this study was the inclusion of postgraduate students in the sample. This enabled comparisions between these two different student groups.

The mean age range for undergraduate students are similar to those reported in other studies on Nigerian students. ${ }^{12}$ -15 As expected, most (92.3\%) of the students were unmarried. There was also a predominance of Christians in the sample. No systematic difference was however, found in health performance by religion.

\section{Physical health status}

There are very few studies on the physical health status of students for comparision. However, the findings of this exploratory study appear to follow expected trends. Physical fitness improved with age up to 30 and then fell as students aged further. Males perceived themselves more able to perform physically demanding tasks than females. Alcohol and tobacco use appear to have a deleterious effect on physical health. Students who engage in recreational physical activity at levels recommended for positive health benefits (i.e. 30 minutes a day for 3 or more days a week) ${ }^{5-9}$ have higher scores. Students living in overcrowded rooms had lower physical health scores. The adverse effect of overcrowding has been reported in other studies. ${ }^{16}$ All these are consistent with rational expectations and with the findings of Parkerson, Broadhead and Tse. Furthermore, those with higher physical health scores were less likely to have had any day of restricted activity or disability in the preceding month. A British study ${ }^{17}$ reported that contrary to what might be expected of this high achieving group, university students had a poorer health status than the general population of a similar age group. As in this study, females had lower health status 
scores than males. However, over one third of the students in that study reported a chronic illness. The most common health problems reported were asthma and musculoskeletal problems.

This study also defines baselines for follow-up in the university community similar to the mental health baselines of Jegede and Baiyewu. ${ }^{18} \mathrm{~A}$ closed community, the university environment provides opportunities for a level of personal health care that most students had never experienced before admission and will perhaps not have again due to factors of location, employment and migration. Health intervention programs can be most efficiently conducted at this level.

Smokers and alcohol users reported lower health scores. This may be due to a direct negative effect of these habits. There is however the possibility that this as well as other effects, are confounded by the lower self-esteem which smokers have. It is plausible that this lower sense of self-worth drives smokers to underrate their health in these study situations.

\section{Disability and number of days of restricted activity}

In this study, the prevalence of physically handicapping conditions among the 724 respondents was $2.2 \%$. Limb deformities resulting in paralysis or paresis were the most common conditions with 3 out of 9 of these students on wheel chairs. The number of days of restricted activity is an important concept providing a direct link between health and student's academic outcomes. Inability to partake in routine daily activities is a valid measure of the burden of ill health in a community. Students in our study lost a total of 750 mandays, an average of over a day per student in the month of interest. This is equivalent to about 18,000 man-hours. This gives an idea of the real cost of ill health.

Disability was reported more often among drinkers and smokers. This finding can be applied in health education to encourage the adoption of healthy lifestyles. Often the choice of a lifestyle is based on conscious assumption of greater benefits than risks. Evidence of concurrent negative effects should therefore provide a better drive for people to avoid life-threatening habits. The study concludes that physical health status of students is associated with various personal and lifestyle factors.

\section{References}

1. Gordon K A. College health in the national blueprint for a healthy campus 2000. Jourial of American College Health 1995; $43: 273-5$.

2. Hall F R and Miller M J. Health policies and procedures for medical students at U. S. medical schools; a progress report. Medical education 1994; $28: 426-32$.

3. Parkerson GR, Broadhead W E and Tse CK. The Duke health profile: a 17 item measure of health and dysfnction. Medical care 1990;28: $1056-71$.

4. Parkerson G R, Gehlbach S H, Wagner E H, James, Clapp and Mulbazer C. The Duke UNC health profile: an adult health status instrument for primary care. Medical care 1981; 19: $806-28$.
5. McAuley D. How much physical activity should we recommend? Proceedings of the 14h WONCA World conference, June 10-14, 1995; Hong Kong, China 1995.

6. Keays $J J$ and Alison $K$. Effects of regular physical exercise on student outcomes. Canadian journal of public health 1995; 86 : $62-70$.

7. Cooper-Patrick L. Exercise and depression in mid life: a prospective study. American journal of public health 1997; 87: $670-3$.

8. Westman K, Wedman-Wester A and Werstman G. Physical activity and perceived health from a gender perspective proceedings of the 14th WONCA world conference, June 10 - 14, 1995; Hong Kong, China 1995.

9. Koff $\mathrm{E}$ and Baumann $\mathrm{C} \mathrm{L}$. Effects of wellness, fitness and sports skills on body image and lifestylc behaviors. Perceptual and motor skills 1997; 84: $555-62$.

10. Ogunremi $O$ and $O$ konofua $F \mathrm{E}$. Abuse of drugs among youths: A University experience. African Journal of Psychiatry 1997; 3: $107-111$.

11. Jegede R O. Personality characteristics and mental health of university students. African Journal of Medicine and Medical Sciences 1979;8:51-60.

12. Jegede $R O$. Personality and mental health characteristics of Nigerian university students. Acta Psychiatrica Scandinavica 1980; 61: $67-80$.

13. Eze U E. Stress and coping strategies of students of Federal College of Education (Special) Oyo. M. P. H. Dissertation, Department of Preventive and Social Medicine, University of Ibadan, Ibadan. 1995.

14. Olowookere J O. Use of psychoactive drugs among students of Ondo State University, Ado Ekiti. M. P. H. Dissertation, Department of Preventive and Social Medicine, University of lbadan, Ibadan. 1997.

15. Ogalla D E. Knowledge, attitude and use of contraceptive methods among unmarried polytechnic students in Ibadan, Nigeria. M. P. H. Dissertation, Department of Preventive and Social Medicine, University of Ibadan, Ibadan. 1998.

16. Fuller T D, Edwards J, Vorakitphokatorn S and Sermsri S Chronic stress and psychological well-being; evidence from Thailand on household overcrowding. Social Science and Medicine $1996 ; 42: 265-80$.

17. Steward-Brown S, Julie E, Jacoby P, Sophie P, Helen D, John $B$ and David $R$. The health of students in institutes of higher education: an important and neglected public health problem. Journal of Public Hcalth Medicine 2000; 22: 492 - 499.

18. Jegede $\mathrm{RO}$ and Baiyewu $\mathrm{O}$. A psychiatric clinic for university of Ibadan students. West African Journal of Medicine 1987; 6 : $121-125$.

19. Verbrugge L M. Triggers and symptoms of disease. Social Science and Medicine 1984; 20:855- 76 . 